\title{
Have we forgotten imaging prior to and after kidney transplantation?
}

\author{
Stan Benjamens ${ }^{1,2}$ (1) $\cdot$ Andor W. J. M. Glaudemans ${ }^{2} \cdot$ Stefan P. Berger ${ }^{3} \cdot$ Riemer H. J. A. Slart $^{2,4} \cdot$ Robert A. Pol $^{1}$
}

Received: 5 January 2018 / Revised: 23 January 2018 / Accepted: 26 January 2018 / Published online: 7 March 2018

(C) European Society of Radiology 2018

\section{Key Points}

- The number of publications on imaging and kidney transplantation is low.

- These publications are poorly cited, as compared with other fields of imaging.

- Conversely, there is a clinical need for evidence-based recommendations.

- Innovative advances for the use of imaging and kidney transplantation are essential.

- An increased focus and adequate research funding are highly anticipated by clinicians.

In the past 20 years outcomes after kidney transplantation (KTX) have improved significantly, as shown by a $10.8 \%$ decline in 10-year graft failure for deceased donor KTX between 1995 and 2005 [1]. The driving force behind this improvement was a research community producing a large number of high-quality clinical trials and clinical guidelines that resulted in more uniform treatment of transplant recipients. However, in the research field of pre- and postKTX medical imaging, guidelines mainly provide recommendations based on "low level of evidence" and "expert opinions" (Fig. 1). New research and publications on imaging techniques for the evaluation of transplant recipients seem to have stagnated, limiting the development of adequate clinical guidelines.

Stan Benjamens

s.benjamens@umcg.nl

1 Department of Surgery, Division of Transplantation Surgery, University Medical Center Groningen, University of Groningen, Hanzeplein 1, 9713 GZ Groningen, The Netherlands

2 Medical Imaging Center, University Medical Center Groningen, University of Groningen, Hanzeplein 1, 9713 GZ Groningen, The Netherlands

3 Department of Internal Medicine, Division of Nephrology, University Medical Center Groningen, University of Groningen, Hanzeplein 1, 9713 GZ Groningen, The Netherlands

4 Department of Biomedical Photonic Imaging, University of Twente, Enschede, The Netherlands

\section{Literature on imaging prior to and after kidney transplantation}

The combination of publication and citation rates is a universally agreed-upon metric to evaluate trends in scientific productivity [7, 8]. No report on scientific productivity focusing on imaging and KTX has been published before. Within this context, we conducted a bibliometric analysis of scientific publications using the Web of Science (WoS) database (0101-1996 to 12-31-2016) and analysed citations over time using the Hirsch index ( $h$-index), which reflects the number of publications with a high impact within the scientific community [9]. For publications on KTX we selected journals from the categories "Transplantation", "Surgery" and "Urology and Nephrology", and for imaging we included journals from the category "Radiology and Nuclear Medicine". Results were subsequently grouped into four categories: (I) Total number of KTX publications in clinical journals, (II) number of ultrasonography (US), magnetic resonance imaging (MRI), computed tomography (CT) and nuclear medicine imaging (NM) publications in imaging journals, (III) number of US, MRI, CT and NM publications on KTX in clinical journals, and (IV) number of KTX publications in imaging journals.

In the last 21 years, $31,001 \mathrm{KTX}$ publications were issued in clinical journals, 1730 (5.6\%) of which focused on imaging (803 on US, 288 on MRI, 528 on CT, 111 on NM). In the same period 216,661 publications were issued in imaging journals, with $642(0.3 \%)$ reporting on radiological or nuclear imaging and KTX (210 on US, 181 on MRI, 163 on $\mathrm{CT}, 88$ on NM). 
Fig. 1 Kidney transplantation guideline recommendations on the use of pre- and post-transplant imaging techniques. Based on recommendations from the following guidelines: (I) European Renal Best Practice (ERBP) [2], (II) Kidney Disease Improving Global Outcome (KDIGO) [3], (III) Kidney Transplantation, European Association of Urology (EAU) [4], (IV) Management of the Failing Kidney Transplant, British Transplantation Society [5], (V) Post-operative Care in the Kidney Transplant Recipient, The Renal Association [6]

\begin{tabular}{|c|c|c|}
\hline Technique & Application & Guidelines \\
\hline \multirow[t]{3}{*}{ Ultrasound } & $\begin{array}{l}\text { Renal and cardiac } \\
\text { screening }\end{array}$ & Expert opinion \\
\hline & $\begin{array}{c}\text { Assesment of allograft } \\
\text { dysfunction }\end{array}$ & $\begin{array}{l}\text { Intermediate } \\
\text { level of evidence }\end{array}$ \\
\hline & $\begin{array}{c}\text { Annual transplant } \\
\text { assesment }\end{array}$ & Expert opinion \\
\hline $\begin{array}{c}\text { Magnetic } \\
\text { Resonance Imaging }\end{array}$ & $\begin{array}{c}\text { Assesment of transplant } \\
\text { oxygenation }\end{array}$ & Not mentioned \\
\hline \multirow[t]{2}{*}{ Computed Tomography } & $\begin{array}{l}\text { CT Angiography } \\
\text { prior to transplant }\end{array}$ & $\begin{array}{l}\text { Low } \\
\text { level of evidence }\end{array}$ \\
\hline & $\begin{array}{l}\text { Abdominal CT } \\
\text { prior to transplant }\end{array}$ & Not mentioned \\
\hline \multirow[t]{3}{*}{ Nuclear Medicine } & $\begin{array}{l}\text { Myocardial perfusion } \\
\text { scan }\end{array}$ & $\begin{array}{l}\text { Low } \\
\text { level of evidence }\end{array}$ \\
\hline & $\begin{array}{l}\text { Renal Scintigraphy for } \\
\text { allograft function }\end{array}$ & Not mentioned \\
\hline & $\begin{array}{c}\text { Bone Mineral Density } \\
\text { measurement }\end{array}$ & $\begin{array}{l}\text { Low } \\
\text { level of evidence }\end{array}$ \\
\hline
\end{tabular}

The yearly publication rates within the field of KTX showed an average increase of $2.3 \%$ per year, which is much lower than the yearly increase of $14.8 \%$ in the total field of imaging (Fig. 2). While the number of imaging publications in clinical journals showed an average annual increase rate of $6.7 \%$ (US 3.2\%, MRI 2.1\%, CT 39.0\%, NM 6.3\%), their share of the total number of KTX publications in clinical journals only rose from $5.6 \%$ to $6.5 \%$ in 21 years (US $2.4 \%$ to $2.7 \%$, MRI $0.9 \%$ to $0.9 \%$, CT $0.5 \%$ to $2.5 \%$, NM $0.3 \%$ to $0.4 \%$ ). The number of publications on KTX in imaging journals increased with $4.8 \%$ for US, $9.3 \%$ for MRI, 5.9 for CT, and decreased with $0.4 \%$ for $\mathrm{NM}$, while their proportion dropped from $0.5 \%$ to $0.3 \%$ in this same period (US $0.7 \%$ to $0.5 \%$, MRI $0.3 \%$ to $0.2 \%$, CT $0.3 \%$ to $0.2 \%$, NM $0.7 \%$ to $0.2 \%$ ).

The average $h$-index for publications in clinical journals in 1996 was 0.2 for publications on imaging and KTX, and 3.3 for non-imaging publications on KTX, showing an annual increase rate of respectively $50.2 \%$ and $16.7 \%$ up until 2016. In imaging journals, the average $h$-index was 0.2 for publications on imaging and KTX and 4.5 for all publications on imaging techniques in general, with a yearly increase rate of respectively $59.4 \%$ and $16.4 \%$.

\section{Lessons learnt}

While innovative techniques and scientific productivity in the field of medical imaging in general have steadily increased, the contribution of medical imaging around KTX to this general increase is neglectable. Development of new imaging techniques for the evaluation of transplant recipients have not succeeded in contributing to significant changes in clinical practice or development of clinical guidelines.

The steady increase in imaging publications has only had a small effect on publications in clinical journals. Compared to other techniques, publications on CT pre- and post-KTX have contributed importantly to this increase. Most likely a higher cardiovascular burden among kidney transplant recipients has led to increased abdominal and cardiac CT imaging in order to determine and lower perioperative mortality risk [10].

As the rate of general imaging publications has grown extensively in the past 10 years, the share of publications on KTX has decreased. Interestingly, NM imaging went from being the highest contributor of scientific publications in the field of KTX to being the smallest. Although there is a reduced but steady number of publications on renal scintigraphy, publications on new and innovative kidney transplant positron emission tomography (PET) tracers, a field with significant clinical potential, are scarce. Citation rates show a similar trend, with a surge for all included publications, but a

Fig. 2 Publications rates on semi-logarithmic scale for the imaging techniques (I) ultrasonography (US), (II) magnetic resonance imaging (MRI), (III) computed tomography (CT) and (IV) nuclear medicine imaging (NM). Showing publications on imaging and kidney transplantation (KTX) separately for clinical and imaging journals, compared to publication rates of total KTX publications in clinical journals and total US/CT/MRI/NM publications in imaging journals 


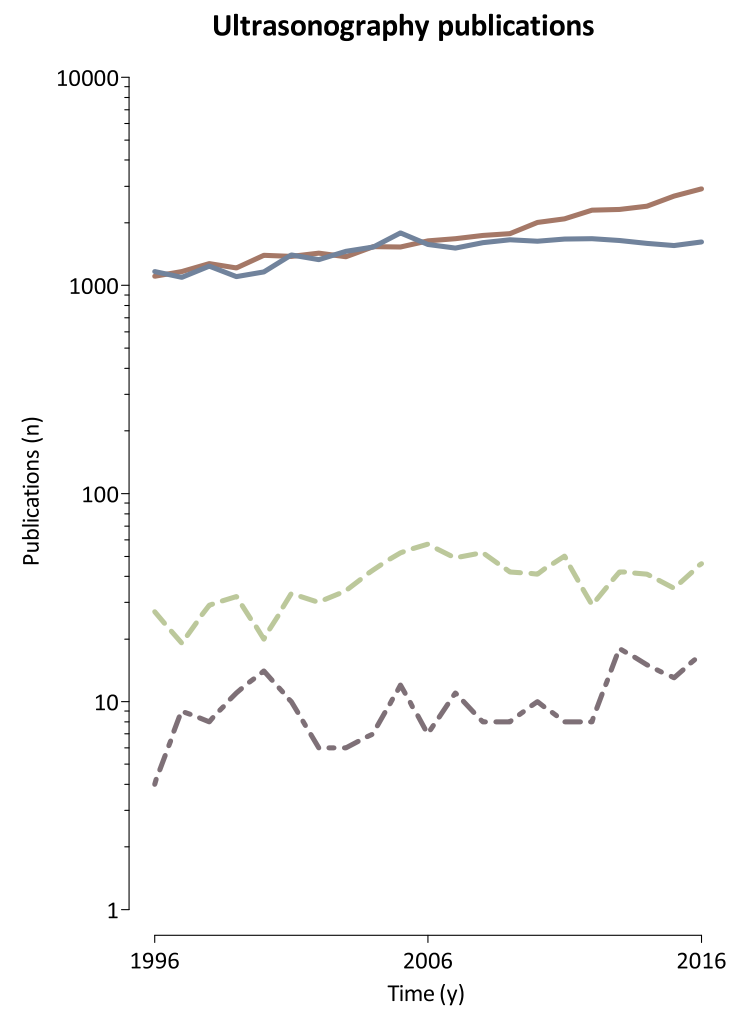

Magnetic resonance imaging publications

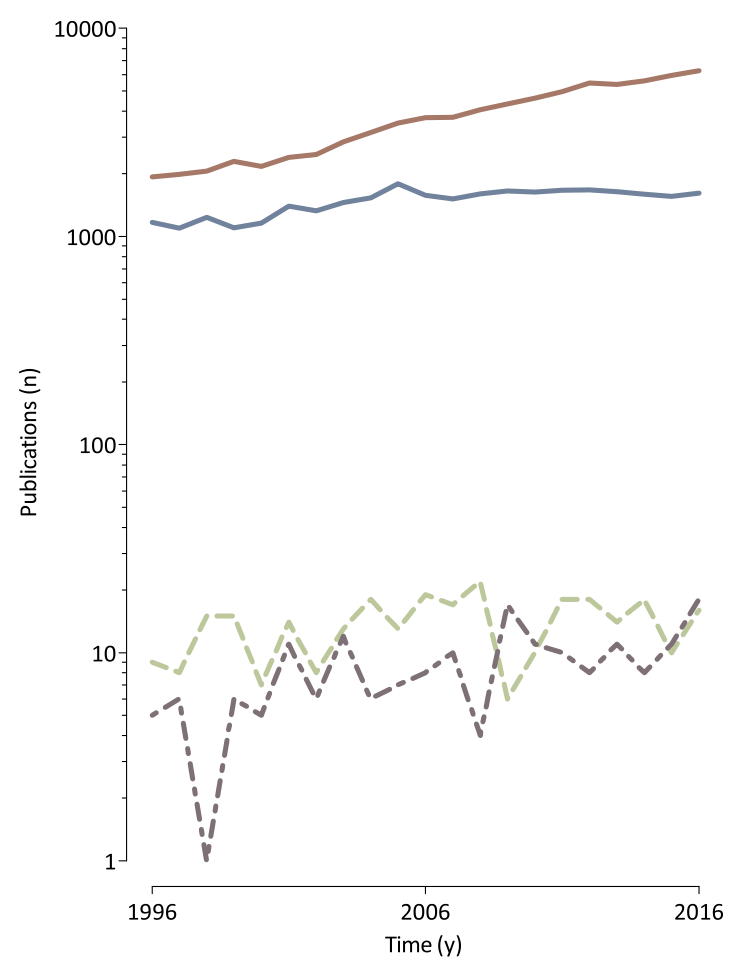

Computed tomography publications
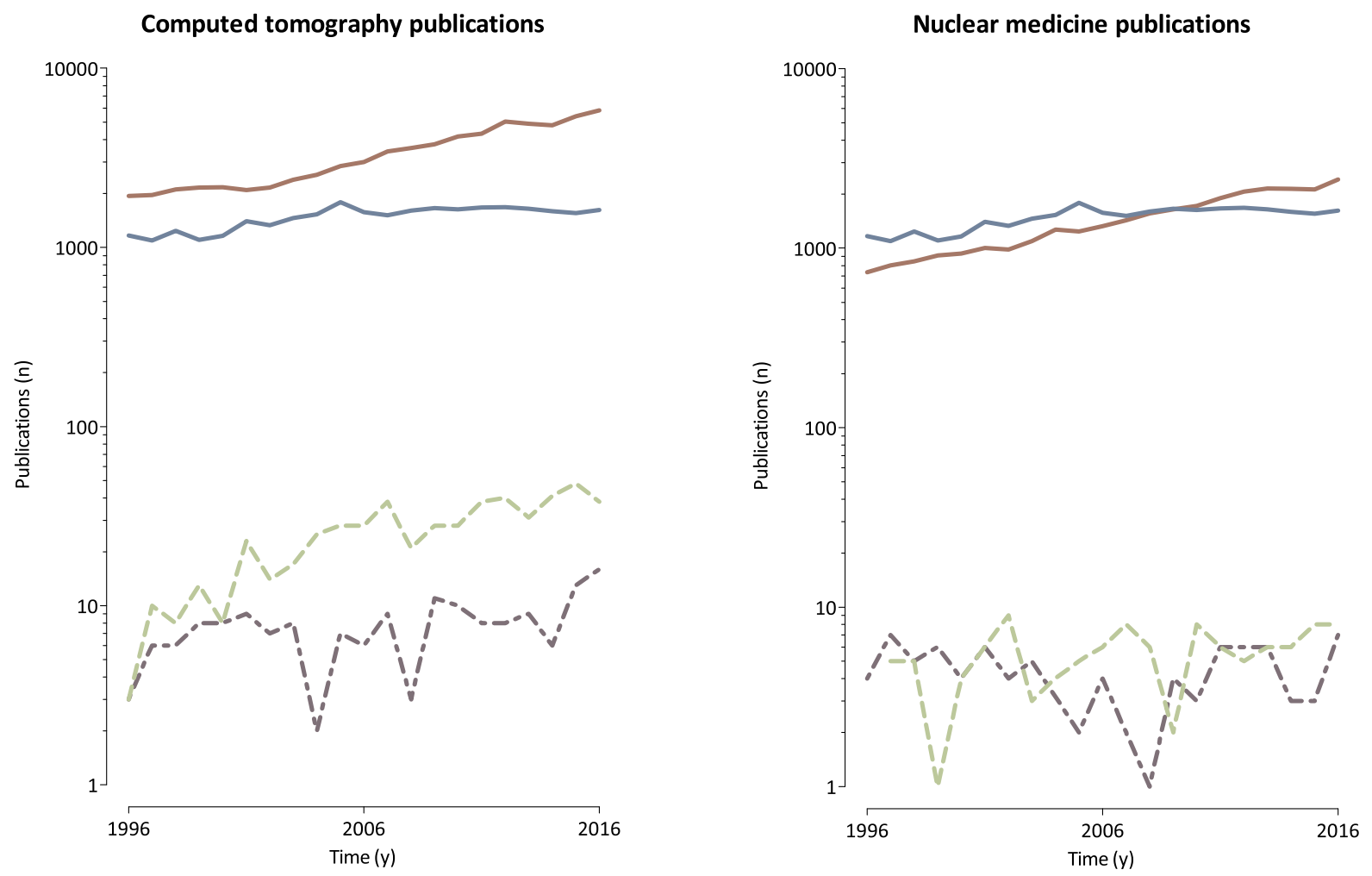

- Total KTX publications in clinical journals

-- Total KTX publications focusing on US/CT/MRI/NM in clinical journals

Total US/CT/MRI/NM publications in imaging journals

-. - Total KTX publications focusing on US/CT/MRI/NM in imaging journals 
lower rate for publications combining imaging and KTX. Studies focusing on PET/CT for the diagnosis of acute allograft rejection showed significant associations in both acute rat renal allograft models and a clinical study, while the sensitivity remained too low for clinical applications [11-14].

As the number of patients on waiting lists for transplantation rises, the proportion of extended-criteria donors has been rising [15]. Development of imaging techniques for graft evaluation and follow-up could contribute to a more reliable graft assessment. Several studies from the research group of Hueper et al., using a kidney transplantation animal model, have shown promising results for the use of MR after transplantation [16-19]. This same research group and several others have initiated studies to translate these outcomes to the clinical setting, showing significant associations between renal allograft function and several MRI sequences in small and heterogeneous cohorts [20-24]. These outcomes have not yet been validated in a larger and more homogenous population of renal transplant recipients and have therefore not yet been introduced to clinical protocols for post-transplant follow-up.

\section{What should we do?}

Clinicians are still in need of methods to reliably discriminate renal allograft rejection from other types of allograft dysfunction. New and promising developments in imaging procedures and production of innovative and specific nuclear tracers have shown positive results in ex vivo and clinical feasibility studies. However, it takes time for these promising techniques to find their way toward clinical studies. Basically, imaging should be implemented in prospective studies with large cohorts, altogether with clinical and biological data. This requires anticipation and inclusion of imaging at the early stage of designing a study. These future studies should focus on clinical translation of these new techniques and require multidisciplinary cooperation. Researchers should explore the opportunities to implement the outcomes of imaging procedures in prediction models with clinical variables. Combining both clinical and imaging variables could lead to clinical prediction models with a high prognostic performance for both shortand long-term renal transplant outcomes.

Clinical guidelines do not have clear evidence-based recommendations on which medical imaging techniques to use in the early post-transplant period. Studies comparing US and renal scintigraphy are lacking, and the role of MR and PET/ $\mathrm{CT}$ has not yet been established in studies with a large cohort. In order to compile comprehensive clinical guidelines, research funding and grants should be more accessible to this relatively small field of research. We should therefore not forget that imaging prior to and after KTX is an important field of research, where there are currently more questions than answers.
Funding The authors state that this work has not received any funding.

\section{Compliance with ethical standards}

Guarantor The scientific guarantor of this publication is Robert A. Pol, $\mathrm{MD}, \mathrm{PhD}$

Conflict of interest The authors of this manuscript declare no relationships with any companies whose products or services may be related to the subject matter of the article.

Statistics and biometry No complex statistical methods were necessary for this paper.

Informed consent Not applicable

Ethical approval Institutional review board approval was not required because data used for this editorial was obtained by means of a bibliometric search.

Methodology

- Bibliometric analysis

\section{References}

1. Hart A, Smith JM, Skeans MA et al (2017) OPTN/SRTR 2015 annual data report: kidney. Am J Transplant 17:21-116

2. Abramowicz D, Cochat P, Claas FH et al (2015) European Renal Best Practice guideline on kidney donor and recipient evaluation and perioperative care. Nephrol Dial Transplant 30:1790-1797

3. Kidney Disease: Improving Global Outcomes (KDIGO) Transplant Work Group (2009) KDIGO clinical practice guideline for the care of kidney transplant recipients. Am J Transplant 9:S1-155

4. Breda A, Olsburgh J, Budde K et al (2017) EAU guidelines on renal transplantation. Edn. presented at the EAU Annual Congress London 2017. 2017

5. Andrews PA, Standards Committee of the British Transplantation Society (2014) Summary of the British Transplantation Society guidelines for management of the failing kidney transplant. Transplantation 98:1130-1133

6. Baker RJ, Mark PB, Patel RK et al (2017) Renal association clinical practice guideline in post-operative care in the kidney transplant recipient. BMC Nephrol 18:172-174

7. Callaham M, Wears RL, Weber E (2002) Journal prestige, publication bias, and other characteristics associated with citation of published studies in peer-reviewed journals. JAMA 287:2847-2850

8. Englesbe MJ, Lynch RJ, Sung RS, Segev DL (2012) Time-trends in publication productivity of young transplant surgeons in the United States. Am J Transplant 12:772-778

9. Alonso S, Cabrerizo FJ, Herrera-Viedma E, Herrera F (2009) hindex: a review focused in its variants, computation and standardization for different scientific fields. J Informetr 3:273-289

10. Cianciolo G, Capelli I, Angelini ML et al (2014) Importance of vascular calcification in kidney transplant recipients cardiovascular disease and vascular calcification in kidney transplant. Am J Nephrol 39:418-426

11. Grabner A, Kentrup D, Edemir B et al (2013) PET with 18F-FDGlabeled T lymphocytes for diagnosis of acute rat renal allograft rejection. J Nucl Med 54:1147-1153

12. Lovinfosse P, Weekers L, Bonvoisin C et al (2016) Fluorodeoxyglucose $\mathrm{F}(18)$ positron emission tomography coupled 
with computed tomography in suspected acute renal allograft rejection. Am J Transplant 16:310-316

13. Reuter S, Schnockel U, Edemir B et al (2010) Potential of noninvasive serial assessment of acute renal allograft rejection by $18 \mathrm{~F}$ FDG PET to monitor treatment efficiency. J Nucl Med 51:1644 1652

14. Reuter S, Schnöckel U, Schröter R et al (2009) Non-invasive imaging of acute renal allograft rejection in rats using small animal FFDG-PET. PLoS One 4:e5296

15. Aubert O, Kamar N, Vernerey D et al (2015) Long term outcomes of transplantation using kidneys from expanded criteria donors: prospective, population based cohort study. BMJ 351:h3557

16. Hueper K, Rong S, Gutberlet M et al (2013) T2 relaxation time and apparent diffusion coefficient for noninvasive assessment of renal pathology after acute kidney injury in mice: comparison with histopathology. Invest Radiol 48:834-842

17. Hueper K, Gutberlet M, Bräsen JH et al (2016) Multiparametric functional MRI: non-invasive imaging of inflammation and edema formation after kidney transplantation in mice. PLoS One 11: e 0162705

18. Hueper K, Schmidbauer M, Thorenz A et al (2017) Longitudinal evaluation of perfusion changes in acute and chronic renal allograft rejection using arterial spin labeling in translational mouse models. J Magn Reson Imaging 46:1664-1672

19. Hueper K, Hensen B, Gutberlet M et al (2016) Kidney transplantation: multiparametric functional magnetic resonance imaging for assessment of renal allograft pathophysiology in mice. Invest Radiol 51:58-65

20. Hueper K, Khalifa AA, Bräsen JH et al (2016) Diffusion-weighted imaging and diffusion tensor imaging detect delayed graft function and correlate with allograft fibrosis in patients early after kidney transplantation. J Magn Reson Imaging 44:112-121

21. Seif M, Eisenberger U, Binser T et al (2016) Renal blood oxygenation level-dependent imaging in longitudinal follow-up of donated and remaining kidneys. Radiology 279:795-804

22. Ren T, Wen C-L, Chen L-H et al (2016) Evaluation of renal allografts function early after transplantation using intravoxel incoherent motion and arterial spin labeling MRI. Magn Reson Imaging 34: 908-914

23. Fan W, Ren T, Li Q et al (2016) Assessment of renal allograft function early after transplantation with isotropic resolution diffusion tensor imaging. Eur Radiol 26:567-575

24. Peperhove M, Vo Chieu VD, Jang M-S et al (2018) Assessment of acute kidney injury with T1 mapping MRI following solid organ transplantation. Eur Radiol 28:44-50 